\title{
O PROCESSO DE TOMADA DE DECISÃO EMPREENDEDORA NA INTERNACIONALIZAÇÃO: ESTUDOS DE CASO COM NOVAS EMPRESAS DE BASE TECNOLÓGICA
}

\author{
Micael Daher Jardim¹, Luís Antônio Dib
}

Universidade Federal do Rio de Janeiro - UFRJ, Rio de Janeiro, (Brasil)

\section{DETALHES DO ARTIGO \\ Histórico do Artigo: \\ Recebido em: 17 de abril de 2020 \\ Aceito: 08 de março de 2021 \\ Disponível online: 01 de maio de 2021}

Sistema de revisão "Double blind
review"

Editor Científico

Ilan Avrichir

Palavras-chaves:

Tomada de decisão

Effectuation e Causation

Empreendedorismo Internacional

\section{RESUMO}

Objetivo: Compreender o processo decisório do empreendedor ao buscar a internacionalização de sua pequena ou média empresa de base tecnológica.

Método: Pesquisa bibliográfica, quatro estudos de caso, com empresas de base tecnológica de pequeno ou médio porte que já se internacionalizaram ou estão em vias de se internacionalizar incluindo entrevista com empreendedores e análise de documentação e informações públicas sobre a empresa.

Principais resultados: Percebeu-se que os empreendedores não utilizam apenas uma lógica de tomada de decisão, mas as duas já descritas na literatura (Effectuation e Causation, segundo Sarasvathy, 2008) de forma cíclica e em três atividades diferentes e complementares: planejamento, execução e improviso.

Relevância/originalidade: É proposto um novo modelo apresentado de forma esquemática, ilustrado pelos estudos de caso e aprofundado na conclusão do artigo.

Contribuições teóricas/metodológicas: A principal contribuição, além do modelo, é a indicação de qual critério oriundo da literatura contribui para que a tomada de decisão empreendedora siga as lógicas de Causation ou de Effectuation.

\section{INTRODUÇÃO}

O principal objetivo da pesquisa apresentada neste artigo foi contribuir para a melhor compreensão do processo de tomada de decisão do empreendedor que internacionaliza uma empresa de base tecnológica. O empreendedorismo é apontado como um processo relevante quando entendido como mola propulsora de inovação e mudança social há quase um século (Schumpeter, 1934). Os empreendedores são vistos como o "motor do capitalismo" (Kahneman, 2013, cap. 24). Novos negócios são os principais geradores de novos empregos (Carre e Thurik, 2010). Empreendedorismo tecnológico teve impacto ainda maior (Audretsch, 1995; Criscuolo, 2014). Governos têm investido no desenvolvimento de melhores políticas públicas para estimular o empreendedorismo (Stam, 2015), cujo estudo continua a ganhar relevância acadêmica (Venkataraman, 2019).

Desde a década de 1970 se estudam casos de pequenas e médias empresas (PMEs) que decidiram se internacionalizar (Johanson e Wiedershein-Paul, 1975). A partir da década de 1990, junto com a Globalização, também se intensificaram os estudos de PMEs que apresentavam internacionalização precoce e, geralmente, acelerada, as chamadas Born Globals (Rennie, 1993). Entretanto, outras PMEs continuavam a se internacionalizar de um modo mais "tradicional", ou seja, de forma lenta e gradual, com comprometimento crescente de recursos para minimizar os riscos da atuação internacional. Este processo foi descrito no Modelo de 
Internacionalização de Uppsala (M-U) (Johanson e Vahlne, 1977 e 1990).

Já o processo de tomada de decisão do empreendedor tem sido estudado com o intuito de entender como decisões são tomadas (Sarasvathy, 2001), que podem ser divididas em duas lógicas de tomada de decisão: Effectuation e Causation (Sarasvathy, 2008). Effectuation ocorreria no processo de tomada de decisão no qual o empreendedor não sabe exatamente onde quer chegar, mas utiliza os recursos que tem à sua disposição; Causation se manifestaria no processo de tomada de decisão no qual o empreendedor sabe onde quer chegar e cria um plano para alcançar os resultados, considerando o futuro como algo mais previsível. Assim, "Causation foca no que é previsível em um futuro incerto. [...] à medida que posso prever o futuro, posso controlá-lo. Effectuation, por outro lado, foca em aspectos controláveis de um futuro imprevisível [...]: à medida em que posso controlar o futuro, não preciso prevê-lo." (Sarasvathy, 2008, p.91). O próprio $M-U$ foi modificado para se compatibilizar com a teoria de Effectuation (Johanson e Vahlne, 2009; Schweizer, Vahlne e Johanson, 2010).

Entretanto, Andersson (2011) apontou que tanto o comportamento quanto o papel do gestor para a internacionalização, utilizando as lógicas de tomada de decisão, não estão bem compreendidas. Ele recomendou que essas lógicas devem ser estudadas em diferentes estágios do processo de internacionalização, inclusive em estágios iniciais. Sugere, ainda, que pesquisas futuras incluam a teoria de Effectuation ao estudar Born Globals. Para Baum (2015), seria necessário realizar mais pesquisas para explicar a relação entre inovação e internacionalização. Por sua vez, Cahen et. al (2017) apontaram a importância de investigar o papel da experiência internacional prévia para a internacionalização de empresas.

Tendo como motivação responder a estas recomendações de pesquisa, buscou-se uma melhor compreensão das decisões empreendedoras ligadas ao processo de internacionalização. Foi desenvolvida pesquisa qualitativa utilizando estudos de casos. O método foi escolhido por permitir compreensão mais profunda e detalhada do problema em questão. Foram estudadas quatro PMEs já internacionalizadas ou em processo de internacionalização, classificadas com NTBFs (New Technologh-Based Firms): empresas novas, de pequeno e médio porte, promotoras de grande mudança tecnológica e inovação utilizando conhecimento de modo intensivo (Autio et. al., 2000). Os casos estudados foram bastante distintos entre si, em relação ao estágio atual de internacionalização, à nacionalidade, ao setor, ao tipo de base tecnológica, à qualificação dos empreendedores, ao diferencial competitivo e ao processo de internacionalização. Para cada caso, buscou-se responder à pergunta: "Como empreendedores tomam decisões ligadas ao processo de internacionalização de suas empresas?".

Percebeu-se que as empresas utilizaram as duas lógicas de tomada de decisão (Effectuation e Causation), e que tais lógicas foram utilizadas de forma cíclica e complementar para guiar etapas diferentes de desenvolvimento. Este achado permitiu a proposição de um modelo para como os empreendedores utilizam as diferentes lógicas de tomada de decisão durante seu processo de internacionalização.

\section{O Processo de Internacionalização de PMEs}

Desviando das teorias econômicas para explicar a configuração internacional das empresas, mais adequadas a empresas grandes com abundância de recursos, foram desenvolvidas as chamadas abordagens comportamentais (Carneiro e Dib, 2008). Tais abordagens buscavam explicar os processos de internacionalização de pequenas e médias empresas, como o Modelo de Uppsala (Johanson e Vahlne, 1977, 1990 e 2009) e modelos de Empreendedorismo Internacional (Oviatt e McDougall, 1994, 2005a e 2005b). O empreendedorismo foi considerado relevante para o entendimento da internacionalização (Zahra, 2005; Schweizer, Vahlne e Johanson, 2010), que passou a ser entendida como um ato de empreendedorismo (Jones e Coviello, 2005).Se o Modelo de Uppsala descrevia bem a internacionalização de empresas que seguiram um processo mais lento e gradual (Johanson e Vahlne, 1977), existiam outras empresas, batizadas como Born Globals (Rennie, 1993), que apresentavam um processo de internacionalização precoce e acelerado(Dib, Rocha e Silva, 2010). Para explicar o fenômeno da internacionalização de PMEs, Johanson e Wiedersheim-Paul (1975) estudaram quatro casos de empresas suecas. Johanson e Vahlne (1977) formalizaram seu processo de internacionalização em quatro etapas, seguidas de maneira sucessiva, estabelecendo gradualmente a empresa no cenário internacional: (1) Atividades esporádicas ou não 


\section{4}

O Processo de Tomada de Decisão Empreendedora na Internacionalização: Estudos de Caso com Novas Empresas de Base Tecnológica

regulares de exportação; (2) Exportação através de representantes independentes; (3) Estabelecimento de representação própria em outro país; e (4) Estabelecimento de unidades produtivas em outros países. Entretanto, outros autores identificaram processos que não podiam ser explicados pelos estágios graduais. Ganitsky (1989) identificou empresas que foram criadas para atender a mercados internacionais a partir de Israel desde sua fundação, batizando-as de Exportadores Inatos. Oviatt e McDougall (1994, p.45) definiram que um "Novo Empreendimento Internacional" seria "um negócio que, desde o seu início, busca conseguir significativa vantagem competitiva com o uso de recursos e vendas de sua produção em múltiplos países". Rennie (1993) identificou empresas australianas que se internacionalizaram desde o início das suas operações, algumas com mais de 75\% das suas vendas provenientes de outros países apenas dois anos após sua fundação, cunhando o termo Born Global. "Born Globals são tipicamente pequenas ou médias novas empresas com grande espírito empreendedor caracterizadas por seus recursos limitados" (Dzikowski, 2018, p.281). Era comum Born Globals serem pequenas empresas de base tecnológica que operavam em mercados internacionais desde os primeiros dias de operação ou que se internacionalizavam cedo e rapidamente (Madsen e Servais, 1997; Hennart, 2013).

Johanson e Vahlne (2009), concordando que o processo de internacionalização de muitas empresas era inconsistente com o $\mathrm{M}-\mathrm{U}$, incorporaram o conceito de Effectuation (Sarasvathy, 2001) à internacionalização. O processo de empreender seria similar ao processo de internacionalizar, considerando as incertezas e limitação de recursos (Schweizer, Vahlne e Johanson, 2010, p.365). Apontaram ainda que os novos tipos de empresas internacionalizadas poderiam ser explicados por mudanças tecnológicas e sociais ocorridas nas décadas posteriores à proposta original do $\mathrm{M}-\mathrm{U}$. Loane (2006) e Nieto e Fernández (2006), por exemplo, mostraram como a internet era importante para a internacionalização de pequenas e médias empresas. Yu et. al. (2005, p.94) analisaram de forma mais ampla o impacto da internet nos negócios: "A adoção da internet nas últimas décadas por mais organizações ao redor do mundo contribuiu de forma expressiva para o recente fenômeno de aceleração da internacionalização, o que é fácil de perceber entre novos negócios."
Johanson e Vahlne (2009, p.175) argumentaram ainda que "internacionalização depende da network da empresa". Johanson e Vahlne (2003) já haviam explicado que networks são criadas a partir de experiências de aprendizado, ou seja, que a experiência internacional da empresa também seria fruto da vida (e das conexões) de seus empreendedores antes ou depois de fundarem as empresas. Segundo Peiris et al. (2012) o estudo sobre Effectuation (Sarasvathy, 2001) passara a ser amplamente utilizado na perspectiva de networks (Anderson 2010; Evers e O'Gorman 2011), modo de entrada em novos mercados (Harms e Schiele 2012), diminuição de riscos e tomada de decisão (Schweizer et al. 2010; Mort et al. 2012). Vahlne e Johanson (2019) questionaram o que mais poderiam fazer para aperfeiçoar o Modelo de Uppsala. Os autores apontaram o nível das redes (networks) como fundamental para a análise da internacionalização, pois muitas vezes as inovações e mudanças de atuação das empresas surgiriam a partir de seus relacionamentos e não no "nível da empresa" como a maioria dos estudos de internacionalização ainda pareciam buscar.

\section{Tomada de decisão empreendedora}

Stevenson (1990, p.23) definiu empreendedorismo como "busca por oportunidades além dos recursos atualmente sob controle". Buscando entender o processo de tomada de decisão empreendedora, Sarasvathy (2001) defendeu que o empreendedor seguiria duas lógicas concorrentes e complementares de pensamento: Effectuation e Causation. Causation seria o modelo tradicional, focado em planejamento prévio e premeditado, em que o empreendedor determina o que quer e busca criar meios de conseguir, confiando em suas previsões. Effectuation, por outro lado, ocorre com o empreendedor que observa o que tem "em mãos" ou que pode conseguir com seus contatos e faz o melhor que pode com aquilo para alcançar algo que the interesse. De uma forma sintética, se no modelo tradicional o empreendedor estabelece um efeito desejado e busca meios de gerá-lo, no modo de Effectuation o empreendedor parte dos meios disponíveis e seleciona que efeitos (desejáveis) podem ser gerados. As lógicas parecem opostas, contudo, não o são necessariamente. De acordo com Yang et al. (2019) Effectuation e Causation são processos cognitivos distintos que o empreendedor 
utiliza. Sarasvathy (2008) explicou os cinco princípios básicos da lógica de Effectuation: (1)“Pássaro na mão": o empreendedor utiliza os recursos que tem disponíveis, como a sua atual rede de contatos, seu conhecimento e os seus recursos produtivos e financeiros; (2) "Perdas Toleráveis": decisões são baseadas mais no limite que o empreendedor toleraria perder do que em uma maximização teórica dos retornos esperados; (3) "Colcha de Retalho": o empreendedor vai construindo uma rede de parceiros, fornecedores e sócios por tentativa e erro; (4) "Piloto no avião": o empreendedor é parte essencial na criação do futuro, não um mero expectador apenas esperando ver se o planejado se realiza; e (5) "Fazer do limão uma limonada": o empreendedor lida com eventos inesperados tentando transformar problemas em oportunidades.

Quanto mais incerto o cenário, menor a chance de o empreendedor utilizar o Causation e maior a chance de utilizar alguma experimentação (Chandler et al., 2011). Dew et al. (2009) mostraram que empreendedores experientes optavam mais por Effectuation, enquanto novatos tendiam para o Causation, o que também foi corroborado por Harms e Schiele (2012). Não é tão claro porque empreendedores experientes utilizam mais o Effectuation, talvez por saberem melhor que previsões são falhas (especialmente em setores emergentes) ou porque possuem mais recursos para serem utilizados (Dew et al., 2009).

Effectuation e Causation são usados simultaneamente cada um em um contexto específico (Guo e Zhang, 2016), pois não há um modelo de tomada de decisões, mas diferentes "tons de cinza" e as decisões são tomadas utilizando as duas lógicas simultaneamente (da Rocha, 2017, p. 19). Sarasvathy e Dew (2005), indicaram que Effectuation prevalece no início do empreendimento, quando há mais incerteza e Causation, em um segundo momento. Sarasvathy et al. (2014) defenderam a aplicação dos processos de Effectuation e Causation para explicar a internacionalização de empresas. Mainela e Puhakka (2009) mostraram que a internacionalização via joint ventures seguia um processo ao mesmo tempo de Effectuation e Causation, Schweizer (2015) corroborou ao mostrar que o processo de internacionalização segue ambas as lógicas.

As redes de contatos (networks) são importantes para o processo de internacionalização, tanto como precursores quanto como fatores de decisão (Lamotte e Colovic, 2015). O envolvimento em networks afeta positivamente a internacionalização, o acesso à capital estrangeiro e a formação de joint ventures, facilitando às empresas o acesso à tecnologia e aos mercados internacionais. Empresas devem utilizar networks e Effectuation para internacionalizar, principalmente se estiverem em ambiente de grande incerteza e de falta de recursos (Sakhdari e Saniei, 2018). Nos casos em que há menos incerteza e abundância de recursos, a lógica causal é preferível. Networks são ainda mais importantes em países em desenvolvimento, que podem contar com menor número de instituições formais, onde a incerteza é maior e o acesso a recursos é menor (Welter e Smallbone 2011), principalmente, em internacionalização de pequenas e médias empresas (Musteen et al. 2014). Andersson (2011) mostrou como Effectuation pode ser uma ferramenta útil no processo de criação de oportunidade pelos membros das suas networks.

Quanto à tomada de decisão no processo de internacionalização, na literatura existe ampla discussão sobre critérios contextuais ou empresariais correlatos com a lógica adotada, conforme ilustrado na Tabela 1. 
O Processo de Tomada de Decisão Empreendedora na Internacionalização: Estudos de Caso com Novas Empresas de Base Tecnológica

Tabela 1: Critérios para tomada de decisão

\begin{tabular}{|l|l|l|l|}
\hline \multirow{2}{*}{ CRITÉRIO } & \multicolumn{2}{|l|}{ LÓGICA DE TOMADA DE DECISÃO } & REFERÊNCIA TEÓRICA \\
\cline { 2 - 3 } & CAUSATION & EFFECTUATION & \\
\hline AMBIENTE & Previsível & Incerto & $\begin{array}{l}\text { Welter e Smallbone (2011) } \\
\text { Sakhdari e Saniei (2018) }\end{array}$ \\
\hline RECURSOS FINANCEIROS & Abundantes & Escassos & $\begin{array}{l}\text { Musteen et al. (2014) } \\
\text { Sarasvathy et al. (2014) } \\
\text { Sakhdari e Saniei (2018) }\end{array}$ \\
\hline MODO DE INTERNACIONALIZAÇÃO & Uppsala & Born Global & $\begin{array}{l}\text { Sarasvathy et al. (2014) } \\
\text { Harms e Schiele (2012) }\end{array}$ \\
\hline EXPERIÊNCIA DO EMPREENDEDOR & Inexperiente & Experiente & $\begin{array}{l}\text { Dew et al. (2009) Sarasvathy } \\
\text { (2008) }\end{array}$ \\
\hline QUALIFICAÇÃO & Negócios (MBA) & Sem qualificação & $\begin{array}{l}\text { Dew et al. (2009) Sarasvathy } \\
\text { (2008) }\end{array}$ \\
\hline NETWORKS & Abundantes & Escassos & $\begin{array}{l}\text { Welter e Smallbone (2011) } \\
\text { Musteen et al. 2014 } \\
\text { Sakhdari e Saniei (2018) }\end{array}$ \\
\hline
\end{tabular}

Muitos elementos da lógica de Effectuation podem ser considerados como incorporados ao Modelo de Uppsala revisado. As principais diferenças são: (1) o modelo de Effectuation possui diversos ciclos de interação entre os stakeholders, e (2) na teoria de Effectuation as oportunidades são consideradas endógenas e não exógenas, como no $\mathrm{M}-\mathrm{U}$. Entretanto, apesar de a oportunidade empreendedora desenvolvida no ajuste do $\mathrm{M}-\mathrm{U}$ ser de caráter exógeno (Schweizer, Vahlne e Johanson, 2010), na versão anterior é afirmado que o processo de desenvolvimento de oportunidades inclui elementos de descoberta, mas também de criação (Johanson e Vahlne, 2009, p. 1420). Pode-se então considerar que o $\mathrm{M}-\mathrm{U}$ evoluiu teoricamente com a incorporação de elementos da teoria de Effectuation.

\section{Metodologia}

O estudo se insere no tema de tomada de decisão de internacionalização pelos empreendedores. Especificamente, buscou-se responder duas questões de pesquisa:

QP1: Existe diferença no processo de tomada de decisão entre empreendedores de empresas Born Globals e de empresas que seguiram processos mais lentos e graduais? Por quê?

QP2: Pode-se verificar a utilização das lógicas de Effectuation e Causation nesse tipo de decisão? Como e por que tais lógicas são utilizadas?

O estudo sobre o tema ainda pode ser considerado fragmentado e incompleto. Observouse, a partir da revisão da literatura, que tanto a lógica do Effectuation quanto a lógica do Causation podem ocorrer em conjunto, e que há fatores ambientais e empresariais que influenciam o uso de uma lógica de tomada de decisão sobre a outra. Contudo, não ficou claro o balanço entre elas, se há alguma preponderância ou se o ambiente empresarial ou mesmo contextual poderia ser alterado para utilizar a lógica mais adequada. Assim, optou-se por utilizar o método de estudo de casos, por ser o mais adequado quando se busca responder perguntas de "como" ou "porquê" (Yin, 2008).

Foram realizadas entrevistas semiestruturadas e em profundidade. Desejava-se que novas ideias surgissem durante o processo, que foi controlado com a ajuda de um roteiro (Whiting, 2008). Buscouse compreender as experiências, os fatos com detalhes, ideias, opiniões e sentimentos de cada entrevistado sobre o assunto. $O$ roteiro foi estruturado com quatro seções principais além da introdução: (1) Histórico pessoal e profissional dos executivos e fundadores; (2) Compreensão do contexto e da empresa no momento da internacionalização; (3) Compreensão do processo de internacionalização; e (4) Compreensão do processo de tomada de decisão. De acordo com Gilbert et. al. (2008) deve-se buscar utilizar processos associados com validade interna, validade dos constructos e validade externa, sabendo que validade interna e do constructo são condições básicas para o alcance da validade externa. As empresas enviaram o relatório final de consultorias e planos de negócios. Também foram buscadas informações nos perfis do LinkedIn das empresas, dos empreendedores e em seus websites. Assim, dados socioeconômicos, 
documentos da empresa, notícias, redes sociais, websites e currículos foram analisadas para a correta triangulação e validade da pesquisa.Foi necessário encontrar empresas que se internacionalizaram ou estavam em vias de se internacionalizar, que fossem de base tecnológica e dispostas a conversar com pesquisadores. Buscou-se empresas com estas características que fossem tão diferentes entre si quanto possível. As quatro empresas estudadas são oriundas do networking dos pesquisadores. As entrevistas foram realizadas por telefone ou videoconferência em janeiro de 2020 e tiveram duração entre 40 e 55 minutos. As entrevistas foram gravadas e transcritas para serem analisadas de acordo com um quadro conceitual elaborado a partir da literatura. As respostas às perguntas de pesquisa foram organizadas individualmente, porém de modo comparativo entre os casos. As conclusões foram enviadas aos entrevistados para verificação de fatos, o que aumentou a consistência do estudo.

A análise baseou-se em quais decisões foram tomadas utilizando a lógica de Effectuation e quais utilizaram a lógica de Causation, sempre no contexto de cada empreendimento, seja na criação do negócio ou produto com a perspectiva de internacionalizá-los, seja na busca de novos mercados ou na escolha deles. De acordo com Eisenhardt (1989) a justaposição de casos pode quebrar lógicas simplistas, de forma que, ao desenvolver múltiplos estudos de caso de forma simultânea e os compara-los, torna-se possível chegar a conclusões valiosas.

\section{DESCRIÇÃO DOS CASOS}

Devido à sensibilidade de informações, as empresas serão chamadas de A, B, C e D. Apesar de possuírem similaridades que permitiram a realização de uma comparação entre seus estudos de caso (base tecnológica, busca pela internacionalização e serem de pequeno ou médio porte), também possuem características distintas: três das empresas são brasileiras ( $A, B$ e D), uma é irlandesa (C); três são da área de tecnologia da informação $(A, C$ e $D)$ e uma é da área de tecnologia de materiais (B); duas atuam no setor de óleo e gás ( $B$ e $D)$, uma atua no setor imobiliário $(C)$ e uma no setor agrário $(A)$.

\section{Empresa A}

Plataforma conecta produtores de café brasileiros a torrefadores europeus, gerando ganhos financeiros para ambos os lados.

A empresa nasceu em 2019 quando um de seus três sócios percebeu que havia um nicho a ser explorado, por se tratar de um mercado grande com baixa utilização de tecnologia. Nenhum dos sócios possuía experiência internacional significativa. A empresa passou por um processo de incubação, os empreendedores levantaram capital e iniciaram imediatamente a busca de clientes em outro país. No início de 2020, todo o faturamento da empresa vinha de clientes europeus.

O empreendedor afirmou que o plano sofreu sérias transformações quando os empreendedores iniciaram a execução, "o mercado não reagiu conforme o esperado" e as barreiras burocráticas foram mais difíceis de transpassar do que o previsto. "A gente só entende para onde vai quando a gente entra no ônibus e começa a ir". O plano previa captar clientes realizando abordagem por telefone ou email, ação que se provou fracassada. Sem muito planejamento, a empresa enviou o Diretor Comercial para explorar o mercado e "ver o que conseguia". Ao visitar as empresas, pessoalmente, o resultado foi significativamente superior. Captaram clientes europeus que permitiram a sua sobrevivência e enviaram, ainda em 2019, dois contêineres totalizando quase um milhão de reais.

\section{Empresa B}

A principal linha de produto da empresa consiste em um material 100\% natural para absorção de petróleo após vazamento offshore (no oceano). Este material é consideravelmente superior aos produtos concorrentes, com absorção muito mais rápida e eficaz, além de permitir a reutilização do petróleo e ser biodegradável. O mercado global é significativo, considerando que foram derramados quase 6 milhões de toneladas de petróleo nos oceanos desde 1970 (ITOPF, 2019).

O empreendedor largou a carreira de executivo depois de quase 20 anos no setor de tecnologia, para empreender na área de produção e comercialização de palmito. Buscou conhecimento em universidade, descobriu e uma tecnologia superior, fazendo-o alterar seus planos iniciais. Levantou capital e iniciou a produção. Contudo a empresa, não se tornou 


\section{8}

O Processo de Tomada de Decisão Empreendedora na Internacionalização: Estudos de Caso com Novas Empresas de Base Tecnológica

internacional, captando clientes locais e operando duas fábricas em território nacional. A empresa possui mais de 8 anos de atuação e atende aos principais clientes do segmento, são mais de 50 ao total (Empresa B, 2020).

A empresa participou de eventos de
internacionalização que oferecem a
empreendedores selecionados consultoria,
mentoria, treinamento, imersão no mercado alvo e
monitoramento e apoio pós-missão. Também busca
de forma deliberada a construção de redes de
relacionamento global: "buscamos parceiros
internacionais ou investidores com experiência
internacional para um projeto de expansão global"
disse o empreendedor.

\section{Empresa C}

Plataforma para agentes imobiliários chegarem rapidamente a um valor preciso para a sua venda. A empresa é um spin off de um grupo do setor imobiliário. O setor imobiliário conta com cerca de 200 mil potenciais clientes na Europa, em um mercado avaliado em mais de 100 milhões de euros para este produto.

O fundador possui mais de 20 anos de experiência como empreendedor, tendo atuado como engenheiro anteriormente. A sua experiência internacional é oriunda de negócios principalmente com empresas inglesas. Possui amplo networking na Inglaterra, para onde seria mais viável iniciar o processo de internacionalização. Segundo o empreendedor, o diferencial está baseado em três pilares: "tecnologia, conhecimento profundo do setor e dados".

A empresa tem planos claros para alcançar o mercado do Reino Unido e posteriormente se expandir para a Europa, tendo resumido suas projeções em um Pitch Deck (documento utilizado para guiar a apresentação para potenciais investidores). Também possui plano de negócios desenvolvido com uma consultoria oriunda da parceria com a Michael Smurfit Graduate Business School, da University College Dublin (UCD). O empreendedor reconhece que é importante ter planos bem definidos, mas percebe a limitação deles, inclusive citando um ditado popular "todo plano é bom até que a primeira bala seja atirada". Acredita, portanto, em fazer o melhor plano possível inicialmente e depois fazer ajustes conforme sua implementação.

\section{Empresa D}

Oferece o serviço para empresas que exploram petróleo offshore. O serviço consiste em reduzir a área para a busca por petróleo por meio de fotos de satélite, pois o petróleo vaza da terra (processo conhecido como exsudação), e marca a superfície do oceano. Este serviço permite a redução da área a explorar, o que reduz significativamente os custos e riscos da operação.

O mundo consumiu, em 2018, o equivalente a mais de dois trilhões de dólares em petróleo (Oil Price, 2020).

A tecnologia foi desenvolvida por um dos empreendedores durante o Doutorado. Convidou uma executiva com experiência profissional internacional para ser cofundadora.

Por meio de uma parceria com Universidade da Califórnia em Los Angeles (UCLA), receberam uma consultoria de negócios "Eles fizeram uma análise de nossa tecnologia e propuseram um plano de negócios, identificando gargalos, formas de internacionalização, mercados potenciais e uma série de insights", relata a empreendedora. "Naquela época, entendemos que faríamos a internacionalização em algum momento, mas focamos nos projetos do Brasil."

A empresa prospectava fora do país e buscava deliberadamente ampliar seu networking com o objetivo de entrar em Houston, EUA. Contudo, além de o mercado "conservador" americano se mostrar reticente à startup brasileira, a demanda por clientes brasileiros era muito grande, o que tirava recursos que poderiam ir para internacionalização.

Uma mudança inesperada no setor - oriunda de uma grave crise - levou as multinacionais que operavam no Brasil de volta às matrizes na Europa e EUA. O que serviu como estímulo para a internacionalização.

Nesta transição, a empreendedora aproveitou a oportunidade, adiaram os planos de ir para os EUA e fecharam contrato com uma empresa portuguesa. Em janeiro de 2020, cerca de $30 \%$ do faturamento vinha de fora do país. 


\section{Discussão dos Resultados}

Os casos possuem um ponto em comum: todos os fundadores planejavam gerir uma empresa global desde muito cedo, contudo, na prática, apenas uma empresa (A) o fez.
Na Tabela 2, um resumo das atividades desenvolvidas ligadas à decisão de internacionalização: planejamento, produto, escolha do mercado, entrada no mercado e entrega de valor.

Tabela 2: Atividades

\begin{tabular}{|c|c|c|c|c|}
\hline EMPRESA & A & B & C & D \\
\hline PLANEJAMENTO & $\begin{array}{l}\text { Realizou planejamento } \\
\text { estratégico no programa } \\
\text { de incubação. }\end{array}$ & $\begin{array}{l}\text { Desenvolveu planos } \\
\text { de negócios. }\end{array}$ & $\begin{array}{l}\text { Desenvolveu plano } \\
\text { de negócios com } \\
\text { apoio de Escola de } \\
\text { Negócios local }\end{array}$ & $\begin{array}{l}\text { Realizou planejamento } \\
\text { estratégico com auxílio } \\
\text { da UCLA. }\end{array}$ \\
\hline $\begin{array}{l}\text { DESENVOLVIME } \\
\text { NTO DO } \\
\text { PRODUTO }\end{array}$ & $\begin{array}{l}\text { Desenvolveu um produto } \\
\text { para conectar produtores } \\
\text { de um país e empresas } \\
\text { clientes de outro. }\end{array}$ & $\begin{array}{l}\text { Desenvolveu } \\
\text { tecnologia inovadora } \\
\text { e superior ao que é } \\
\text { comercializado em } \\
\text { todo mundo. }\end{array}$ & $\begin{array}{l}\text { Desenvolvido para } \\
\text { ser útil no mercado } \\
\text { global. Com a } \\
\text { utilização de bancos } \\
\text { de dados nacionais, } \\
\text { a customização por } \\
\text { país não será trivial. } \\
\text { Tem gerado valor à } \\
\text { clientes locais e } \\
\text { provado o seu valor } \\
\text { para a } \\
\text { internacionalização. }\end{array}$ & $\begin{array}{l}\text { Desenvolveu tecnologia } \\
\text { inovadora e superior ao } \\
\text { que é comercializado } \\
\text { em todo mundo. }\end{array}$ \\
\hline $\begin{array}{l}\text { ESCOLHA DO } \\
\text { MERCADO }\end{array}$ & $\begin{array}{l}\text { Escolheu a Europa por } \\
\text { motivos mercadológicos } \\
\text { e, conseguiu, ingressar no } \\
\text { país. }\end{array}$ & $\begin{array}{l}\text { Desde o início, } \\
\text { planejam } \\
\text { internacionalização, } \\
\text { mas ainda não } \\
\text { obtiveram êxito. }\end{array}$ & $\begin{array}{l}\text { Escolha do mercado } \\
\text { tem relação com } \\
\text { networking do } \\
\text { empreendedor, } \\
\text { proximidade } \\
\text { psíquica e física. }\end{array}$ & $\begin{array}{lr}\text { Europa } & \text { por } \\
\text { proximidade } & \text { psíquica } \\
\text { networking. } & \\
\end{array}$ \\
\hline $\begin{array}{l}\text { ENTRADA NO } \\
\text { MERCADO }\end{array}$ & $\begin{array}{l}\text { Planejou realizar vendas à } \\
\text { distância e teve que } \\
\text { realizar uma mudança no } \\
\text { plano. }\end{array}$ & $\begin{array}{l}\text { Participaram de feiras } \\
\text { e planejaram, mas } \\
\text { ainda não captaram } \\
\text { clientes } \\
\text { internacionais. }\end{array}$ & $\begin{array}{l}\text { Optando em ir } \\
\text { primeiro para UK e } \\
\text { depois para a } \\
\text { Europa e só depois } \\
\text { para outros } \\
\text { continentes. } \\
\text { Empreendedor } \\
\text { busca levantar } \\
\text { capital e entrar } \\
\text { rapidamente nos } \\
\text { mercados } \\
\text { escolhidos. }\end{array}$ & $\begin{array}{l}\text { Se deveu à } \\
\text { oportunidade } \\
\text { inesperada } \\
\text { dificuldade de executar } \\
\text { o plano de entrar nos } \\
\text { EUA. }\end{array}$ \\
\hline $\begin{array}{l}\text { ENTREGA DE } \\
\text { VALOR }\end{array}$ & $\begin{array}{l}\text { Planejou o envio dos } \\
\text { contêineres, mas teve } \\
\text { muito mais dificuldade do } \\
\text { que o esperado. } \\
\text { A captação de } \\
\text { cafeicultores também } \\
\text { não foi fácil, e a empresa } \\
\text { teve que buscar de forma } \\
\text { improvisada solucionar a } \\
\text { questão, buscando } \\
\text { desenvolver network de } \\
\text { forma deliberada. }\end{array}$ & $\begin{array}{l}\text { Conseguiu clientes } \\
\text { nacionais e um bom } \\
\text { aporte de capital. } \\
\text { Desta forma, focaram } \\
\text { no mercado nacional } \\
\text { e o plano de } \\
\text { internacionalização } \\
\text { tem sido postergado. }\end{array}$ & $\begin{array}{l}\text { Os clientes atuais } \\
\text { estão satisfeitos, } \\
\text { contudo a empresa } \\
\text { pretender se } \\
\text { capitalizar e validar } \\
\text { o produto antes de } \\
\text { expandir para } \\
\text { outros países. }\end{array}$ & $\begin{array}{l}\text { Conseguiu clientes } \\
\text { nacionais. Desta forma, } \\
\text { focaram no mercado } \\
\text { nacional e o plano de } \\
\text { internacionalização foi } \\
\text { postergado, por } \\
\text { mudança no contexto, } \\
\text { buscaram a } \\
\text { internacionalização, e } \\
\text { passaram a atuar no } \\
\text { mercado europeu. }\end{array}$ \\
\hline
\end{tabular}


O Processo de Tomada de Decisão Empreendedora na Internacionalização: Estudos de Caso com Novas Empresas de Base Tecnológica

Já a Tabela 3 resume a análise em relação aos principais critérios trazidos da literatura (Tabela 1).

Tabela 3: Empresas analisadas com base nos critérios

\begin{tabular}{|c|c|c|c|c|}
\hline CRITÉRIOS & $A$ & B & C & $D$ \\
\hline Ambiente & Previsível & Incerto & Incerto & Previsível \\
\hline Recursos Financeiros & Escasso & Abundante & Escasso & Escasso \\
\hline $\begin{array}{c}\text { Modo de } \\
\text { Internacionalização }\end{array}$ & Born Global & Incerto & Incerto & Incerto \\
\hline $\begin{array}{l}\text { Experiência do } \\
\text { Empreendedor }\end{array}$ & $\begin{array}{l}\text { Equipe com pouca } \\
\text { experiência } \\
\text { profissional }\end{array}$ & $\begin{array}{l}\text { Vários executivos } \\
\text { experientes }\end{array}$ & $\begin{array}{l}\text { Um executivo } \\
\text { experiente } \quad \text { com } \\
\text { experiência } \\
\text { internacional }\end{array}$ & $\begin{array}{l}\text { Um empreendedor } \\
\text { experiente }\end{array}$ \\
\hline Qualificação & $\begin{array}{l}\text { Engenheiros } \\
\text { Advogados. }\end{array}$ & $\begin{array}{l}\text { Diversas } \\
\text { formações, } \\
\text { inclusive } \quad \text { em } \\
\text { negócios. }\end{array}$ & $\begin{array}{l}\text { Doutorado na área } \\
\text { técnica da empresa } \\
\text { e Mestrado em } \\
\text { Administração. }\end{array}$ & $\begin{array}{lr}\text { Engenheiro } & \text { sem } \\
\text { formação } & \text { em } \\
\text { negócios. } & \end{array}$ \\
\hline Networks & $\begin{array}{l}\text { Inexistente } \\
\text { previamente. Busca } \\
\text { ativa. }\end{array}$ & $\begin{array}{l}\text { Inexistente } \\
\text { previamente. } \\
\text { Busca ativa. }\end{array}$ & $\begin{array}{l}\text { Inexistente } \\
\text { previamente. Busca } \\
\text { ativa. }\end{array}$ & $\begin{array}{l}\text { Nada indica } \\
\text { existência ou uma } \\
\text { busca ativa. }\end{array}$ \\
\hline $\begin{array}{l}\text { Processo de Tomada de } \\
\text { decisão }\end{array}$ & $\begin{array}{l}\text { Causation } \\
\text { Effectuation }\end{array}$ & $\begin{array}{l}\text { Causation } \\
\text { Effectuation }\end{array}$ & $\begin{array}{l}\text { Causation } \\
\text { Effectuation }\end{array}$ & $\begin{array}{l}\text { Causation } \\
\text { Effectuation }\end{array}$ \\
\hline
\end{tabular}

Fonte: Autores

Ambiente

Setor de óleo e gás pode apresentar grandes variações na oferta e no preço - o que leva a bruscas mudanças da dinâmica. Mercado imobiliário ou do café é mais previsível, contudo, na visão dos empreendedores, seus produtos inovadores geram incerteza e o processo de experimentação torna-se mais necessário.

Sakhdari e Saniei (2018) recomendaram o uso do Effectuation para a internacionalização, principalmente em contexto de grande incerteza e abundância de recurso. As duas empresas que atuavam em ambiente de grande incerteza ( $B$ e D) tinham perfil bem diferente em relação a recursos. $A$ Empresa B estava planejando o processo de internacionalização utilizando a lógica do Causation. A Empresa $D$ buscou utilizar a mesma lógica e, curiosamente, foi exatamente o ambiente incerto que favoreceu sua internacionalização

\section{Recursos Financeiros}

A, C e D possuíam poucos recursos, o que as levou a buscar mais network - justamente a prática recomendada (Welter e Smallbone, 2011). Não está claro na literatura qual lógica é utilizada em empresas com poucos recursos. Por um lado, poucos recursos aumentam a incerteza, fazendo a decisão pender para o Effectuation (Sakhdari e Saniei, 2018), por outro, empreendedores de sucesso utilizam o Effectuation e isso por ser explicado por eles possuírem mais recursos (Dew et al., 2009).

B vê o processo de internacionalização de forma causal. Sua estratégia consiste em criar um bom plano e executá-lo. Para isso deve buscar recurso financeiros e agir com velocidade. A estratégia de C é a mesma. Contudo, as empresas que se internacionalizaram - por mais que possuíssem estratégias similares - não o fizeram desta forma, mas aproveitando de oportunidades que surgiram. D planejou e tentou Houston e acabou indo para 
Portugal. Empresa A buscou conexões pessoais após abandonar o plano de vendas à distância e conseguiu a internacionalização. O que ocorreu com a Empresa $D$ e com a Empresa $A$ não foi resultado de planejamento utilização de grandes recursos financeiros, mas de estar atento as oportunidades e aproveitá-las, mesmo quando os planos falharem.

\section{Modo de Internacionalização}

A única empresa estudada que é claramente uma Born Global é a Empresa A. Por ser baseada na internet, isto deve ter acelerado seu processo de internacionalização (Loane, 2006 e Nieto e Fernández, 2006). É a que possui menor diferencial tecnológico, foi a única que se internacionalizou, ao contrário do era esperado (Dib et. al., 2010).

B e D com grande diferencial tecnológico advindo de pesquisa em universidades brasileiras, também possuíam mercado interno significativo, o que conteve o processo.

Cahen et. al. (2017) afirmaram que empresas com internacionalização tardia conseguiam capitalizar suas competências e conseguiam mais vantagens competitivas o que ocorre em C.

\section{Experiência do Empreendedor}

Mais experiência permite maior capacidade de internacionalização (Cahen et. al., 2017), tendo em vista a internacionalização de $D$, que só foi possível devido à experiência da empreendedora. Não é possível avaliar se a falta de experiência dos empreendedores acelerou ou retardou o processo de A.A equipe de $B$ é muito mais diversa e experiente, ainda não internacionalizaram e contam fortemente com os planos desenvolvidos e com a própria capacidade de prever o mercado.

Cahen et. al (2017) afirmaram que a habilidade de gestão internacional da equipe gerencial acelera o processo de internacionalização. Porém, dentre os casos estudados, a empresa com menor experiência (e menor experiência internacional) foi a que internacionalizou mais rapidamente.

\section{Qualificação}

É possível que o acesso à informação, a facilidade de acesso à ferramentas e à qualificação informal contribuem para que qualificação formal não tenha importância significativa na velocidade da internacionalização, não tendo sido observado diferença alguma entre as empresas.

\section{Networks}

As duas empresas que, de fato, possuem clientes no exterior, A e D possuem pelo menos uma pessoa chave alocada em outro país com a principal função de buscar conexões e ampliar a rede. Afirmaram não ser possível terceirizar a atividade de vendas.

B busca network de forma deliberada, com a inserção de um novo sócio e participação em eventos. $C$ busca internacionalizar com investimento grande em marketing e agência de publicidade, o empreendedor possui rede de contatos e deve utilizá-la no processo de internacionalização, apesar de não prever isso em seus planos. Todas as empresas parecem valorizar redes de relacionamento as cultivando, quando existentes ou as construindo de forma deliberada. A importância das redes profissionais para a internacionalização é defendida por Johanson e Vahlne (2009), por Lamotte e Colovic (2015) e Sakhdari e Saniei (2018) entre outros autores.

\section{Processo de Tomada de Decisão}

As quatro empresas desenvolveram plano de negócios, duas delas com auxílio de consultoria. Porém, nenhuma seguiu o plano à risca. Em todos os casos foram utilizadas tanto a lógica de Effectuation quanto a de Causation.

D começou o processo com uma perspectiva de planejar e prever o futuro (Causation). Ao longo da trajetória, a empresa percebeu como a distância psíquica é importante e que ela é muito maior em relação aos Estados Unidos do que em relação à Europa. Os americanos eram avessos a risco e demandavam a necessidade de relações pessoais para o desenvolvimento de negócios. Acabaram se internacionalizando com uma demanda de uma empresa portuguesa (Effectuation).

O Fundador de $\mathrm{C}$ reconhecia a distância entre seus planos e a realidade encontrada na sua trajetória como empreendedor. Acreditava que deveria planejar e executar com bastante velocidade. Por isso, pretendia executar assim que conseguisse o capital necessário.

A única empresa que, de fato, nasceu internacional foi a empresa que buscava vantagem competitiva por ser internacional (A). As outras, por mais que tenham uma vantagem competitiva global ( $B$ e $D$ ) e mesmo possuindo recursos financeiros (B) não conseguiram internacionalizar rapidamente. $O$ 


\section{2}

O Processo de Tomada de Decisão Empreendedora na Internacionalização: Estudos de Caso com Novas Empresas de Base Tecnológica

que pode ser explicado pela distância psíquica, pela fraca rede de relacionamentos ou mesmo por falta de experiência em internacionalização dos executivos da empresa.

\section{CONCLUSÃO}

Para melhor compreender o processo de tomada de decisão do empreendedor que internacionaliza uma empresa de base tecnológica foi desenvolvido estudo de casos. A partir dos resultados do estudo, pode ser proposto um modelo conceitual, apresentado nesta conclusão.

As questões da pesquisa que serviram de base para o estudo:

QP1: Existe diferença no processo de tomada de decisão entre empreendedores de empresas Born Globals e de empresas que seguiram processos mais lentos e graduais? Por quê?

Não foram observadas diferenças de processos de tomada de decisão entre empresas com diferentes modos ou velocidades de internacionalização. 0 processo de decisão é similar, pois nenhuma dessas empresas usa apenas uma lógica de tomada de decisão, mas ambas. O ponto em comum entre as empresas é ter poucos recursos.

QP2: Pode-se verificar a utilização das lógicas de Effectuation e Causation nesse tipo de decisão? Como e por que tais lógicas são utilizadas?

A utilização de ambas lógicas foi observada. Os empreendedores utilizam o Causation e o Effectuation tanto simultaneamente (Guo e Zhang, 2016) quanto em "tons de cinza" (Rocha, p. 19, 2017) como já era esperado. O que foi percebido no presente estudo é que ainda mais relevante do que a simultaneidade e os tons de cinza é a utilização das duas lógicas de forma intercalada e cíclica, o que nós deu a ideia para propor um modelo.Todos os casos apresentaram etapas em que um tipo de atividade se sobrepõe à outra, sendo utilizadas de forma intercalada, conforme modelo ilustrado na Figura 1.

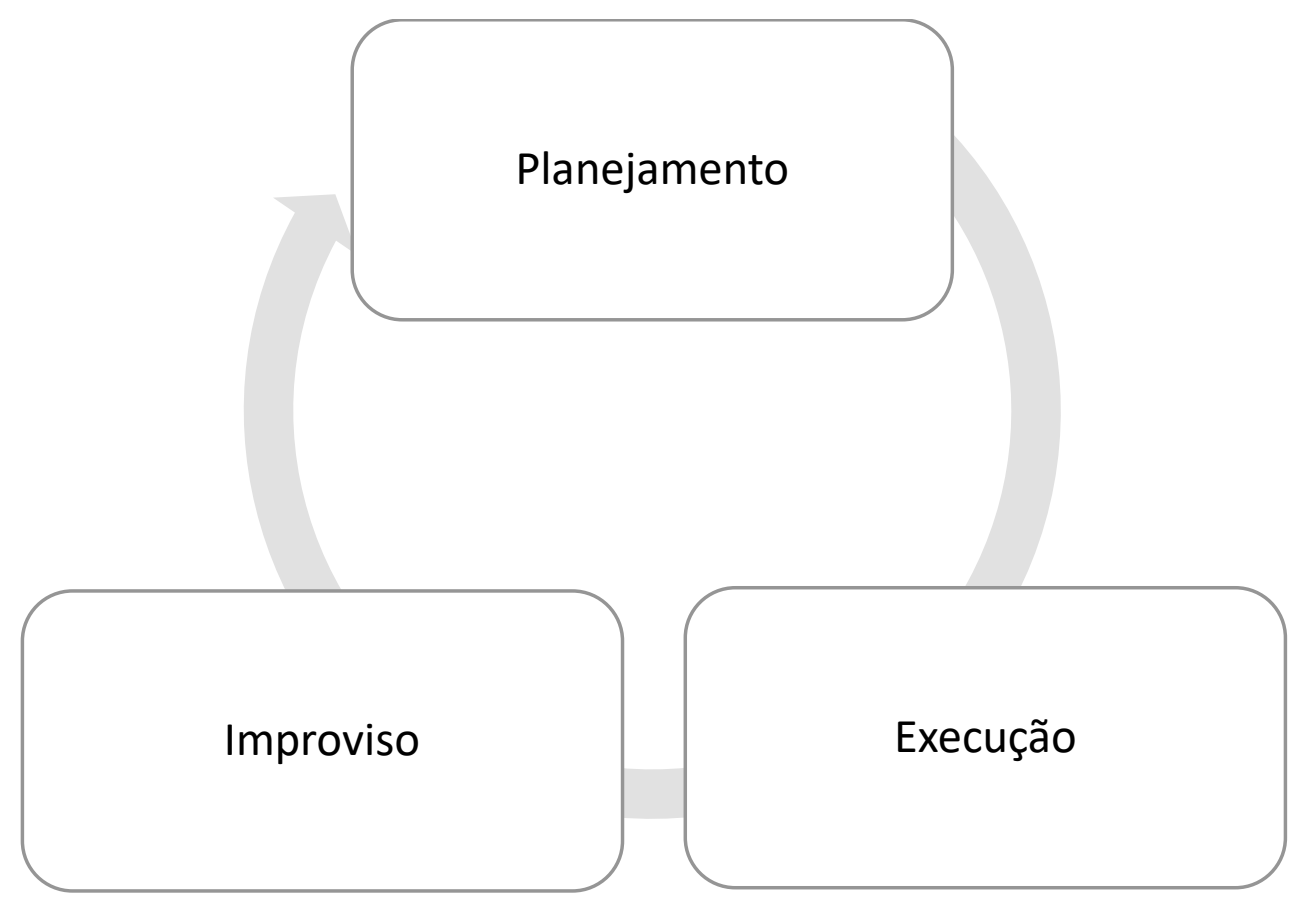

Figura 1. Modelo

Fonte: Autores

As três atividades buscam resultados diferentes, utilizam recursos diferentes, possuem limitações diferentes e apresentam lógica de decisão diferente, como descrito na Tabela 4. 
Tabela 4: Explicação das etapas do Modelo

\begin{tabular}{|c|c|c|c|c|}
\hline ETAPAS & O QUE BUSCA & O QUE UTILIZA & LIMITAÇÃO & $\begin{array}{l}\text { LÓGICA DA } \\
\text { DECISÃO }\end{array}$ \\
\hline Improviso & $\begin{array}{l}\text { Aprendizado e } \\
\text { diminuição } \\
\text { das incertezas }\end{array}$ & $\begin{array}{l}\text { Criatividade, experiência } \\
\text { prévia, perda tolerável. }\end{array}$ & $\begin{array}{l}\text { Limitação de recursos, } \\
\text { pouco alinhamento. }\end{array}$ & Effectuation \\
\hline $\begin{array}{l}\text { Planejament } \\
\text { o }\end{array}$ & $\begin{array}{l}\text { Recursos e } \\
\text { Alinhamento }\end{array}$ & $\begin{array}{l}\text { Ferramentas gerenciais, } \\
\text { pesquisa, informações } \\
\text { vindas das outras fases. }\end{array}$ & Ausência de ambiente real. & Causation \\
\hline Execução & Expansão & $\begin{array}{l}\text { Conhecimento acumulado, } \\
\text { planejamento e capacidade } \\
\text { operacional. }\end{array}$ & $\begin{array}{l}\text { Aversão à experimentação } \\
\text { e dificuldade de assimilar } \\
\text { novas informações. Rigidez. }\end{array}$ & Causation \\
\hline
\end{tabular}

Fonte: Autores

O empreendedor não sabe exatamente quais são as possibilidades e com isso não consegue saber onde quer chegar. Apesar de saber que quer montar um negócio, não sabe exatamente qual negócio e, apesar de saber que quer gerir uma empresa internacional, não sabe em quais países entrar ou como realizar este processo. A etapa de improviso, na qual ele utiliza mais fortemente a lógica do Effectuation, acaba por gerar conhecimento necessário para que a empresa possa alcançar algum resultado factível. Tal resultado pode ser o desenvolvimento de uma parceria, o lançamento de um produto novo, a conquista de um cliente ou mesmo a aquisição de conhecimento. Este resultado diminui incertezas e contribui para o aumento do comprometimento.

Ao saber onde quer chegar e avaliar que tem recursos - ou que consegue levantá-los - o empreendedor planeja detalhadamente, muitas vezes apoiado por consultores. Surge o Plano de Negócios, Plano de Internacionalização, Plano de Marketing ou algo do gênero. Podem ser levantadas mais informações de forma mais estruturada por meio de pesquisa de mercado, análise da concorrência ou estudos de fornecedores.

Empreendedores sem experiência tendem a ignorar a etapa de Improviso e empreendedores sem qualificação tendem a não ser capazes (ou a estar convencidos da necessidade) de desenvolver um bom Planejamento. Com o plano em mãos, os empreendedores são capazes de levantar recursos e executar o plano. Contudo, o plano sempre será limitado. Serve para embasar parte da execução e se esgota, pois não contempla adversidades imprevistas e ou oportunidades inesperadas. A Tabela 5 utiliza os casos para ilustrar cada uma das etapas. 
O Processo de Tomada de Decisão Empreendedora na Internacionalização: Estudos de Caso com Novas Empresas de Base Tecnológica

Tabela 5: Ilustração das etapas com os casos

\begin{tabular}{|c|c|c|c|c|}
\hline ETAPAS & $A$ & B & $D$ & C \\
\hline Improviso & $\begin{array}{l}\text { Ao sentar-se em uma } \\
\text { lanchonete, o empreendedor } \\
\text { encontrou buscou conhecer } \\
\text { as pessoas que estavam ali e } \\
\text { encontrou parceiros que se } \\
\text { tornaram valiosos para o } \\
\text { negócio. }\end{array}$ & $\begin{array}{l}\text { Visitar centros de } \\
\text { pesquisa estudando } \\
\text { possibilidades do que } \\
\text { fazer com o palmito }\end{array}$ & $\begin{array}{l}\text { Aproveitar a } \\
\text { mudança de cenário } \\
\text { com a mudança da } \\
\text { inteligência das } \\
\text { empresas europeias } \\
\text { e americanas e } \\
\text { mudar as operações } \\
\text { para Portugal }\end{array}$ & $\begin{array}{l}\text { Criação de uma } \\
\text { plataforma para gestão } \\
\text { de dados, que vira outra } \\
\text { plataforma para } \\
\text { avaliação de imóveis }\end{array}$ \\
\hline Planejamento & $\begin{array}{l}\text { Realizar estudo dos principais } \\
\text { clientes, redigir plano de } \\
\text { negócios, análise das } \\
\text { projeções financeiras. Fez } \\
\text { parte }\end{array}$ & $\begin{array}{l}\text { Planejamento } \\
\text { Estratégico interno. }\end{array}$ & $\begin{array}{l}\text { Planejamento } \\
\text { estratégico } \\
\text { desenvolvido em } \\
\text { parceria com a UCLA }\end{array}$ & $\begin{array}{l}\text { Planejamento } \\
\text { Estratégico } \\
\text { desenvolvido em } \\
\text { parceria com a Michael } \\
\text { Smurfit e Pitch Deck } \\
\text { para levantar capital } \\
\text { desenvolvido } \\
\text { internamente. }\end{array}$ \\
\hline Execução & $\begin{array}{l}\text { Visitar os potenciais clientes } \\
\text { e fechar contrato }\end{array}$ & $\begin{array}{l}\text { Levantar capital, } \\
\text { executar instalação } \\
\text { fabril, iniciar produção } \\
\text { e captar clientes } \\
\text { segundo o plano. }\end{array}$ & $\begin{array}{l}\text { Contratação de } \\
\text { representantes nos } \\
\text { EUA }\end{array}$ & $\begin{array}{l}\text { Desenvolvimento do } \\
\text { produto e captação dos } \\
\text { primeiros clientes. }\end{array}$ \\
\hline
\end{tabular}

Fonte: Autores

Este estudo possui algumas limitações a serem consideradas: os empreendedores podem enviesar voluntária ou involuntariamente as informações, podem não se lembrar bem de fatos ou do processo cognitivo utilizado e podem ocultar informações por diversos motivos. Outra limitação é a forma de colher os dados, por meio de entrevistas. Seria mais rico observar o empreendedor tomando as decisões.

Para pesquisas futuras recomenda-se a validação do modelo proposto de forma quantitativa, como também sugerido por (Vahlne e Johanson, 2019). Também podem ser usados meios alternativos de pesquisa qualitativa, como o de Qualitative Comparative Analysis (Parente e Federo, 2019), capazes de investigadar mais a fundo diferenças processuais, porém a partir de outra organização de de pesquisa e coleta de dados.

Este estudo evidenciou algumas áreas merecedoras de pesquisas mais aprofundadas: a importância do diferencial tecnológico para conseguir a rápida expansão global; como o mercado interno forte diminui o incentivo à internacionalização e a criação de network para fins específicos. Além disso, deve-se verificar se o modelo cíclico proposto seria exaurido após o estágio inicial de empreendimento ou se ele permaneceria quando a empresa atingisse uma maior maturidade.

\section{Referências}

Anderson, A. R.; Dodd, S.D.; Jack, S. (2010). Network practices and Entrepreneurial Growth. Scandinavian Journal of Management, 26, p. 121-133.

Andersson S. (2011) International Entrepreneurship, Born Globals and the theory of Effectuation. Journal of Small Business Enterprise Development 18(3):627-643

Audretsch, D. (1995). Innovation and Industry Evolution. MIT Press, Cambridge MA.

Autio, E.; Sapienza, H.; Almeida, J. (2000) 'Effects of age at entry, knowledge intensity, and imitability on international growth', Academy of Management Journal, Vol. 43, No. 5, pp.909-924.

Baum, M.; Schwens, C.; Kabst, R. (2015). A latent class analysis of small firms' internationalization 
patterns, Journal of World Business, Volume 50, Issue 4 Pages 754-768, ISSN 1090-9516.

Cahen, F. R.; Oliveira Junior, M. M.; Borini, F. M. (2017). The internationalization of new technologybased firms from emerging markets. International Journal of Technology Management, 74(1/2/3/4), 23.

Cannone, G.; Ughetto, E. (2014). Born Globals: A cross-country survey on high-tech start-ups. International Business Review, 23(1), 272-283.

Carneiro, J.; Dib, L.A. (2007) Avaliação comparativa do escopo descritivo e explanatório dos principais modelos de internacionalização de empresas. InternexT - Revista Eletrônica de Negócios Internacionais da ESPM, v. 2, n. 1, p. 1-25.

Chandler, G. N.; Detienne, D. R.; Mckelvie, A.; Mumford, T. V. (2011). Causation and Effectuation processes: A validation study. Journal of Business Venturing, 26(3), 375-390.

Choquette, E.; Rask, M. ; Sala, D.; Schröder, P. (2017). Born Globals - Is there fire behind the smoke? International Business Review, 26(3), 448-460.

Criscuolo, C.; Gal, P.N.; Menon, C. (2014). The dynamics of employment growth: New evidence from 18 countries. OECD Science, Technology and Industry Policy Papers. No. 14, OECD Publishing.

Da Rocha, A., Simões, V. C., De Mello, R. C.; Carneiro, J. (2017). From global start-ups to the borderless firm: Why and how to build a worldwide value system. Journal of International Entrepreneurship, 15(2), 121-144.

Dew, N, Read, S. Sarasvathy, S. Wiltbank, R. (2009). Effectual versus Predictive Logics in Entrepreneurial Decision-Making: Differences between Experts and Novices. Journal of Business Venturing, vol. 24, no. 4. 287-309.

Dib, L. A., Rocha, A.; da Silva, J. F. (2010). The Internationalization Process of Brazilian Software Firms and the Born Global Phenomenon: Examining Firm, Network, and Entrepreneur Variables." Journal of International Entrepreneurship, vol. 8, no. 3. pp. 233-253.
Dzikowski, P. (2018). A bibliometric analysis of Born Global firms. Journal of Business Research, 85, 281-294.

Elo, S.; Kyngäs, H. (2008). The qualitative content analysis process. Journal of Advanced Nursing, 62(1), 107-115.

Evers, N.; O'Gorman, C. (2011) Improvised internationalization in new ventures: the role of prior knowledge and networks. Entrepreneuship and Regional Development 23(7/8):549-574.

Fernández, Z.; Nieto, M. (2006). Impact of ownership on the international involvement of SMEs. Journal of International Business Studies. 37, 340-351.

Ganitsky, J. (1989). Strategies for innate and adoptive exporters: lessons from Israel's case. International Marketing Review, 6/5, p.50-65.

Guo, R.; Cai, L.; Zhang, W. (2016). Effectuation and Causation in new internet venture growth. Internet Research. 26. 460-483. 10.1108/IntR-01-2015-0003.

Harms, R. Schiele, H. (2012) Antecedents and consequences of Effectuation and Causation in the international new venture creation process. Journal of International Entrepreneurship.

Hennart, J.F. (2013). The Accidental Internationalists: A Theory of Born Globals. Entrepreneurship Theory and Practice, 38(1), 117135.

How much oil has the world really consumed. Oil Price (2019). Disponível em: https://oilprice.com/Energy/Crude-Oil/How-MuchCrude-Oil-Has-The-World-Really-Consumed.html Acesso em: 09, fevereiro, 2020.

Johanson J., Wiedersheim-Paul F. (1975) The internationalization of the firm - four Swedish cases. Journal of Management Studies 12:305-322

Johanson, J., Vahlne, J. E. (1977). The internationalization process of the firm $-A$ model of knowledge development and increasing foreign market commitments. Journal of International Business Studies, 8(1), 23-32. 


\section{6}

O Processo de Tomada de Decisão Empreendedora na Internacionalização: Estudos de Caso com Novas Empresas de Base Tecnológica

Johanson, J., Vahlne, J. E. (1990). The mechanism of internationalization. International Marketing Review, 7(4).

Johanson, J., Vahlne, J. E. (2003). Business relationship learning and commitment in the internationalization process. Journal of International Entrepreneurship, v. 1, n. 1, p. 83- 101.

Johanson, J., Vahlne, J. E. (2009). The Uppsala internationalization process model revisited: From liability of foreignness to liability of outsidership. Journal of International Business Studies 40, 1411-1431 (2009) doi:10.1057/jibs.2009.2Jones, M. V.; Coviello, N. E. (2005) Internationalisation: conceptualising an entrepreneurial process of behaviour in time. Journal of International Business Studies, v. 36, n. 3, p. 284303, 2005.

Kahneman, D. (2013) Thinking Fast and Slow [reprint]. Farrar, Strauss and Giroux: New York.

Knight, G. A.; Cavusgil, S. T. (1996) The Born Global firm: a challenge to traditional internationalization theory. In: Cavusgil, S. E Madsen, K. (eds.) Export internationalizing research - enrichment and challenges, (Advances in International Marketing, 8). Nova York: JAI Press. P.11-26.

Lamotte, O.; Colovic, A. (2015). Early Internationalization of New Ventures From Emerging Countries: The Case of Transition Economies. M@n@gement, 18(1), 8.

Loane, S. (2006) The role of the internet in the internationalization of small and medium sized companies. Journal of International Entrepreneurship, 3, p.263-277.

Madsen, K.; Servais, P. (1997) "The Internationalization of Born Globals: An Evolutionary Process?" International Business Review, vol. 6, no. 6, pp. 561-583.

Mainela, T.; Puhakka, V. (2009) Organizing new business in a turbulent context: opportunity discovery and Effectuation for IJV development in transition markets. Journal of International Entrepreneurship 7(2):111-134
Mort, G.; Weerawardena, J.; LIESCH, P. (2012) Advancing entrepreneurial marketing: evidence from Born Global firms. Eur J Mark 46(3):542-561

Musteen, M.; Datta, D.K.; Francis, J. (2014) Early internationalization by firms in transition economies into developed markets: the role of international networks. Global Strategy Journal 4(3):221-237

Oil Tanker Spill Statistics 2019. ITOPF (2019). Disponível em: https://www.itopf.org/knowledgeresources/data-statistics/statistics. Acesso em: 09, fevereiro, 2020.

Oviatt, B. M.; Mcdougall, P. P. (1994) Toward a theory of international new ventures. Journal of International Business Studies, p. 45-64.

Oviatt, B. M.; Mcdougall, P. P. (2005a). Defining international entrepreneurship and modeling the speed of internationalization. Entrepreneurship Theory and Practice, 29(5), 537-554.

Oviatt, B. M.; Mcdougall, P. P. (2005b). The internationalization of entrepreneurship. Journal of International Business Studies, 36(1), 2-8.

Parente, T.; e Federo, R. (2019) Qualitative comparative analysis: justifying a neo-configurational approach in management research. RAUSP Management Journal, 54 (4), 399-412.

Peiris, I. K.; Akoorie, M. E. M.; Sinha, P. (2012). International entrepreneurship: A critical analysis of studies in the past two decades and future directions for research. Journal of International Entrepreneurship, 10(4), 279-324.

Rennie, M. W. (1993). Born Global. The McKinsey Quarterly, v. 4, n. 4, p. 45-52.

Sakhdari K., Saniei S. (2018) Effectuation, Causation and the Revised Uppsala Model: A Behavioral Analysis of Iranian SMEs' Internationalization. In: Faghih N., Zali M. (eds) Entrepreneurship Ecosystem in the Middle East and North Africa (MENA). Contributions to Management Science. 
Sarasvathy, S. (2001). Causation and Effectuation: Toward A Theoretical Shift from Economic Inevitability to Entrepreneurial Contingency. The Academy of Management Review. 26.

Sarasvathy, S. (2008). Effectuation: Elements of Entrepreneurial Expertise. Edward Elgar Publishing Limited, Cheltenham, UK.

Sarasvathy, S. D.; Dew, N. (2005) Entrepreneurial logics for a technology of foolishness. Scandinavian Journal of Management, v. 21, n. 4, p. 385-406.

Sarasvathy, S.; KUMAR, K.; YORK J. G.; BHAGAVATULA, S. (2014). An effectual approach to international entrepreneurship: overlaps, challenges, and provocative possibilities. Entrepreneurship Theory Practice.

Schumpeter, J. A, Redvers, O. (1934) The Theory of Economic Development: An Inquiry into Profits, Capital, Credit, Interest, and the Business Cycle. Cambridge, Massachusetts: Harvard University Press.

Schweizer, R., Vahlne, J.E., Johanson, J. (2010) Internationalization as an entrepreneurial process. Journal of International Entrepreneurship 8(4):343370.

Schweizer, R. (2015) Decision-making during small and medium-sized enterprises' internationalization-Effectuation vs. Causation. Journal of International Entrepreneurship Dev $8(1): 22-41$

Stam, E. (2015). Entrepreneurial Ecosystems and Regional Policy: A Sympathetic Critique. Discussion Paper Series 15-07. Utrecht University School of Economics, Kriekenpitplein, Netherland.
Stevenson, H. H., Jarillo, J. C. (1990). A paradigm of entrepreneurship: Entrepreneurial management, Strategic Management Journal, 11, pp. 17-27.

Vahlne, J.-E., \& Johanson, J. (2019). The Uppsala model: Networks and micro-foundations. Journal of International Business Studies. doi:10.1057/s41267019-00277-x

Welter, F.; Smallbone, D. (2011) Institutional perspectives on entrepreneurial behavior in challenging environments. Journal of Small Business Management 49(1): 107-125

Whiting, L. S. (2008). Semi-structured interviews: guidance for novice researchers. Nursing Standard, 22(23), 35-40.

Yin, R. K. (2018) Case Study Research and Applications: Design and Methods. SAGE.

Yu, J.; De Koning, A.; Oviatt, B. M. (2005) Institutional and economic influences on Internet adoption and accelerated firm internationalization. In: Katz J, Shepherd D (eds) International Entrepreneurship. Advances in entrepreneurship, firm emergence and growth 8:85-110.

Zahra, S. A. (2005) A theory of international new ventures: A decade of research. Journal of International Business Studies, v. 36, n. 1, p. 20-28.

Zander, I.; Mcdougall-Covin, P.; Rose, E. L. (2015). Born Globals and international business: Evolution of a field of research. Journal of International Business Studies, 46(1), 27-35. 


\section{SOBRE OS AUTORES}

Micael Daher Jardim - Universidade Federal do Rio de Janeiro - UFRJ, Rio de Janeiro, (Brasil). E-mail: micaeldjardim@hotmail.com. Orcid id: https://orcid.org/0000-0003-2698-9657

Luís Antônio Dib - Universidade Federal do Rio de Janeiro - UFRJ, Rio de Janeiro, (Brasil). E-mail: dib@coppead.ufrj.br. Orcid id: https://orcid.org/0000-0002-5102-8578

\section{ENTREPRENEUR DECISION MAKING PROCESS DURING THE INTERNATIONALIZATION OF A COMPANY: CASE STUDY WITH BRAZILIAN TECH BASED SMALL AND MEDIUM-SIZED ENTERPRISES}

Micael Daher Jardim, Luís Antônio Dib

Universidade Federal do Rio de Janeiro - UFRJ, Rio de Janeiro, RJ (Brasil)

\begin{tabular}{l}
\hline ARTICLE DETAILS \\
Article history: \\
Received: 17 April 2020 \\
Accepted: 08 March 2021 \\
Available online May: 01 th 2021 \\
Double Blind Review System \\
Scientific Editor \\
Ilan Avrichir \\
\hline Keywords \\
Decision Making \\
Effectuation \\
Causation \\
International entrepreneurship
\end{tabular}

ABSTRACT
Objective: To understand the cognitive process of the entrepreneur during the
internationalization of a SMBs.
Method: Bibliographical research, four case studies, with tech small and
medium-sized enterprises that are already or are becoming international
enterprises. These studies included: interview with the entrepreneurs and
documentation analysis.
Main Results: Entrepreneurs do not use only one logic of decision making, but
both already described in the literature (Effectuation and Causation,
Sarasvathy, 2008) are used in cyclical and complementary way through
planning, execution and improvisation.
Relevance/originality: The main contribution is the proposal of a model that
explains the basic activities an entrepreneur undertake in order to reach
desired results. The model is proposed via a chart with an explanatory table and
a table to illustrate using the cases.
Theoretical/methodological contributions: It is the first study to synthesize in a
table the studies that correlates decision making with contextual or
entrepreneurial criteria.




\section{EL PROCESO EMPRESARIAL DE TOMA DE DECISIONES EN LA INTERNACIONALIZACIÓN: ESTUDIOS DE CASO CON NUEVAS EMPRESAS BASADAS EN TECNOLOGÍA}

Micael Daher Jardim, Luís Antônio Dib

Universidade Federal do Rio de Janeiro - UFRJ, Rio de Janeiro, RJ (Brasil)

\begin{tabular}{l}
\hline HISTORIA DEL ARTÍCULO \\
\hline Historia del Artículo: \\
Recibido: 17 de Abril de 2020 \\
Aceptado: 08 de Marcha de 2021 \\
Disponible en línea: 01 de Mayo 2021 \\
Double Blind Review System \\
Editor Científico \\
Ilan Avrichir \\
\hline Palabras-clave: \\
Toma de decisiones \\
Effectuation y Causation \\
Emprendimiento internacional
\end{tabular}

\section{RESUMEN}

Objetivo: comprender el proceso cognitivo del emprendedor al buscar la internacionalización de su pequeña o mediana empresa de base tecnológica.

Método: investigación bibliográfica, cuatro estudios de caso, con pequeñas y medianas empresas de base tecnológica que ya se han internacionalizado o están en proceso de internacionalización, incluidas entrevistas con empresarios y análisis de documentación e información pública acerca de la empresa.

Principales Resultados: Se observó que los emprendedores no usan solo una lógica de toma de decisiones, sino los dos ya descritos en la literatura (Effectuation and Causation, según Sarasvathy, 2008) de manera cíclica y en tres actividades diferentes y complementarias: planeamiento, ejecución e improvisación.

Pertinencia y originalidad: se propone un nuevo modelo presentado de forma esquemática, ilustrado por los estudios de caso y explicado en la conclusión del artículo.

Contribuciones teóricas o metodológicas: la contribución principal, además del modelo, es la indicación de qué criterio derivado de la literatura contribuye a la toma de decisiones empresariales siguiendo la lógica de causalidad o effectuation. Tal compilación no tiene precedentes en la literatura de negocios internacionales.

\section{Como citar este artigo:}

Jardim, M., \& Dib, L. (2021). O Processo de Tomada de Decisão Empreendedora na Internacionalização: Estudos de Caso com Novas Empresas de Base Tecnológica. Internext, 16(2), 152-169. doi: http://dx.doi.org/10.18568/internext.v16i2.605 